\title{
Rock property modelling and sensitivity analysis for hydrocarbon exploration in OSSY field, Niger Delta Basin
}

\author{
Alexander Ogbamikhumi ${ }^{1}$. Osakpolor Marvellous Omorogieva ${ }^{2}$
}

Received: 23 October 2020 / Accepted: 2 March 2021 / Published online: 14 March 2021

(c) The Author(s) 2021

\begin{abstract}
The application of quantitative interpretation techniques for hydrocarbon prospect evaluation from seismic has become so vital. The effective employment of these techniques is dependent on several factors: the quality of the seismic and well data, sparseness of data, the physics of rock, lithological and structural complexity of the field. This study adopts reflection pattern, amplitude versus offset (AVO), Biot-Gassmann fluid substitution and cross-plot models to understand the physics of the reservoir rocks in the field by examining the sensitivity of the basic rock properties; P-wave velocity, S-wave velocity and density, to variation in lithology and fluid types in the pore spaces of reservoirs. This is to ascertain the applicability of quantitative seismic interpretation techniques to explore hydrocarbon prospect in the studied field. The results of reflection pattern and AVO models revealed that the depth of interest is dominated by Class IV AVO sands with a high negative zero offset reflectivity that reduces with offset. The AVO intercept versus gradient plot indicated that both brine and hydrocarbon bearing sands can be discriminated on seismic. Fluid substitution modelling results revealed that the rock properties will favourably respond to variation in oil saturation, but as little as $5 \%$ gas presence will result in huge change in the rock properties, which will remain constant upon further increments of gas saturation, thereby making it difficult to differentiate between economical and sub-economical saturations of gas on seismic data. Rock physics cross-plot models revealed separate cluster points typical of shale presence, brine sands and hydrocarbon bearing sands. Thus, the response of the rock properties to the modelling processes adopted favours the application of quantitative interpretation techniques to evaluate hydrocarbon in the field.
\end{abstract}

Keywords AVO modelling · Fluid substitution · Quantitative interpretation · Rock physics $\cdot$ Cross-plot analysis

\section{Introduction}

Quantitative seismic interpretation (QI) deals with rock properties; these are the properties of rocks that influence the propagation of seismic wave (Mavko et al. 2020). They basically include: compressional wave velocity, shear wave velocity, density and their numerous derived attributes which include P-wave impedance, Poisson's ratio, S-wave impedance, Mu-Rho, and Lambda-Rho (Dewar 2001). The observed amplitude on seismic data, sometimes interpreted as direct hydrocarbon indicators (DHI's), is as a result of

Alexander Ogbamikhumi

alexander.ogbamikhumi@uniben.edu

1 Department of Geology, University of Benin, Benin-City, Nigeria

2 Department of Marine Geology, Nigerian Maritime University, Okerenkoko, Nigeria contrast or variation in these rock properties at the boundary between two geological or geophysical interfaces. These variations are as a result of changes in lithology and or fluid in the subsurface (Ogbamikhumi et al. 2018b; Sohail and Hawkes 2020). Analysis of these amplitudes provides valuable information across field, leading to a better understanding of the subsurface geologic heterogeneity related to lithology and fluid effect (Ogbamikhumi et al. 2017a, b). Variation of amplitude with offset analysis of these subsurface property changes had provided valuable insight into hydrocarbon exploration in clastic environment (Ross 2000).

Amplitude variation with offset (AVO) technique poses information about the subsurface elastic rock properties, and was developed to help define the fluid content of hydrocarbon reservoir (Alvarez et al. 2017). Its application involves creating synthetic models and comparing the models with real pre-stacked data. 
Analysis of the cross-plot of amplitude versus offset (AVO) attributes that are derived from modelled synthetic gathers, is a key technique that can be applied to characterize reservoirs. Accurate analysis is required to establish the AVO classes of reservoirs present in the study field, making it possible to concentrate on some particular scenarios and execute case specific analysis. Although several types of AVO reservoirs might possibly co-exist at the same time in the same field, evaluating all will make the assessment of the AVO response more time-

consuming (Paul and Marianne 2006; Uko and Emudianughe 2014; Avseth et al. 2016; Ogararue and Anine 2016; Ohaegbuchu and Igboekwe 2016; Toshe, 2017).

Robinson et al. (2005) in their work discovered that fluid substitution is a necessary aspect of interpreting seismic-amplitude and AVO anomalies. Fluid substitution modelling process is an important aspect of seismic attribute studies as it provides the interpreter with a valuable tool to model the seismic responses for various fluid scenarios (Smith et al. 2003; Rizwan, 2018). Fluid substitution model is essential to make dependable estimate of density, Vs, and $\mathrm{Vp}$ of variable fluid types and fluid saturations from their respective in situ well logs. This process presents information about the sensitivity of the rock properties to changes in fluid content and lithology (Assefa et al. 2003; Robinson et al. 2005; Ogbamikhumi et al. 2018a). The substitution process is normally done during modelling to give an indication of the modelled seismic response sensitivity to the presence of gas or brine in the reservoirs.

Cross plot analysis and forward modelling such as AVO and fluid substitution modelling are seriously considered when possible direct hydrocarbon indicators (DHI) that result from variation in elastic rock properties such as bright spot ( on structure brightening), dim spot ( on structure dimimg), flat spot are seen on the full stack seismic data (Paul and Marianne 2006; Das and Chatterjee 2016; Kumar et al. 2016; Singha and Chatterjee 2017; Ogbamikhumi and Igbinigie 2020). The present study employs analysis of reflection pattern, AVO, fluid substitution and cross-plot models to evaluate the sensitivity of rock attributes derived from wells and establish the application of quantitative seismic interpretation techniques for the prospectivity of reservoirs in the OSSY field, onshore Niger Delta Basin.

\section{Geology of the study area}

The study field is located in the Niger Delta Basin. The basin is a tertiary delta situated in the Gulf of Guinea (Fig. 1). Wells drilled through the delta penetrated three major lithostratigraphic units: the sandy Benin Formation, the intercalated Agbada Formation and the shaley Akata Formation (Short and Stauble 1967). The basin is structurally complex and divided into several depo-belts that become younger basin-ward. Most discovered hydrocarbon bearing reservoir is embedded in the intercalated sands of the Agbada formation which is enclosed mostly within simple and roll over anticlinal traps.

\section{Datasets and methodology}

A field wide full stack 3D reflectivity seismic and well data (reservoir tops, gamma-ray log, density $\log$, resistivity log, calliper log, compressional and shear sonic logs) were available for the study (Fig. 1). Pre-stack data were not available for the study. The well logs were subjected to several conditioning techniques to improve upon the quality; filtering, despiking, splicing and quality checked with calliper logs for wash out zones. The quality of the well logs afterwards was good and suitable to achieve the objectives of this work. The study was conducted mainly with Hampson Russell (HR) software suites. The study adopted four different modelling techniques: reflection pattern, fluid substitution, AVO, and cross-plot models to analyse the sensitivity of rock properties to lithologies and fluid changes.

Reflection pattern analysis was initially done on the well $\log$, as a prerequisite to AVO modelling to examine the signal amplitude strength at geophysical boundaries. It is a forward modelling convolutional process that involves generating synthetic seismogram preferably with the deepest available well in the field. The synthetic was generated using a deterministic wavelet extracted from the seismic. This technique can reveal several information about the seismic data especially lithology and fluid properties, which could serve as quality control to our geophysical modelling.

Fluid substitution modelling was carried out on the reservoir sands to test the sensitivity of their rock properties to various fluid conditions. The Gassmann's equation relates the bulk moduli of mineral matrix, the porous rock frame, and the pore fluids (Gassmann 1951). Chopra and Castagna (2014) demonstrated that Gassmann's equations do not take into account modification of the rock frame properties by the pore fluids during fluid substitution. Thus, the frame modulus was taken as the modulus of the frame in the presence of the wetting fluid. The application of this equation is a two-part process, whereby we first determine the bulk modulus of the porous rock frame (the bulk modulus of the rock devoid of its initial pore fluid, also known as the "dry frame" bulk modulus), after which we calculate the bulk modulus of the rock saturated with any fluid of our choice (Smith et al. 2003). From the field report, the in situ fluid within the zone of interest has been established to be oil. During modelling, the reservoir was replaced with different saturation for both oil and gas $(0 \%, 5 \%, 20 \%$, and $80 \%)$. 


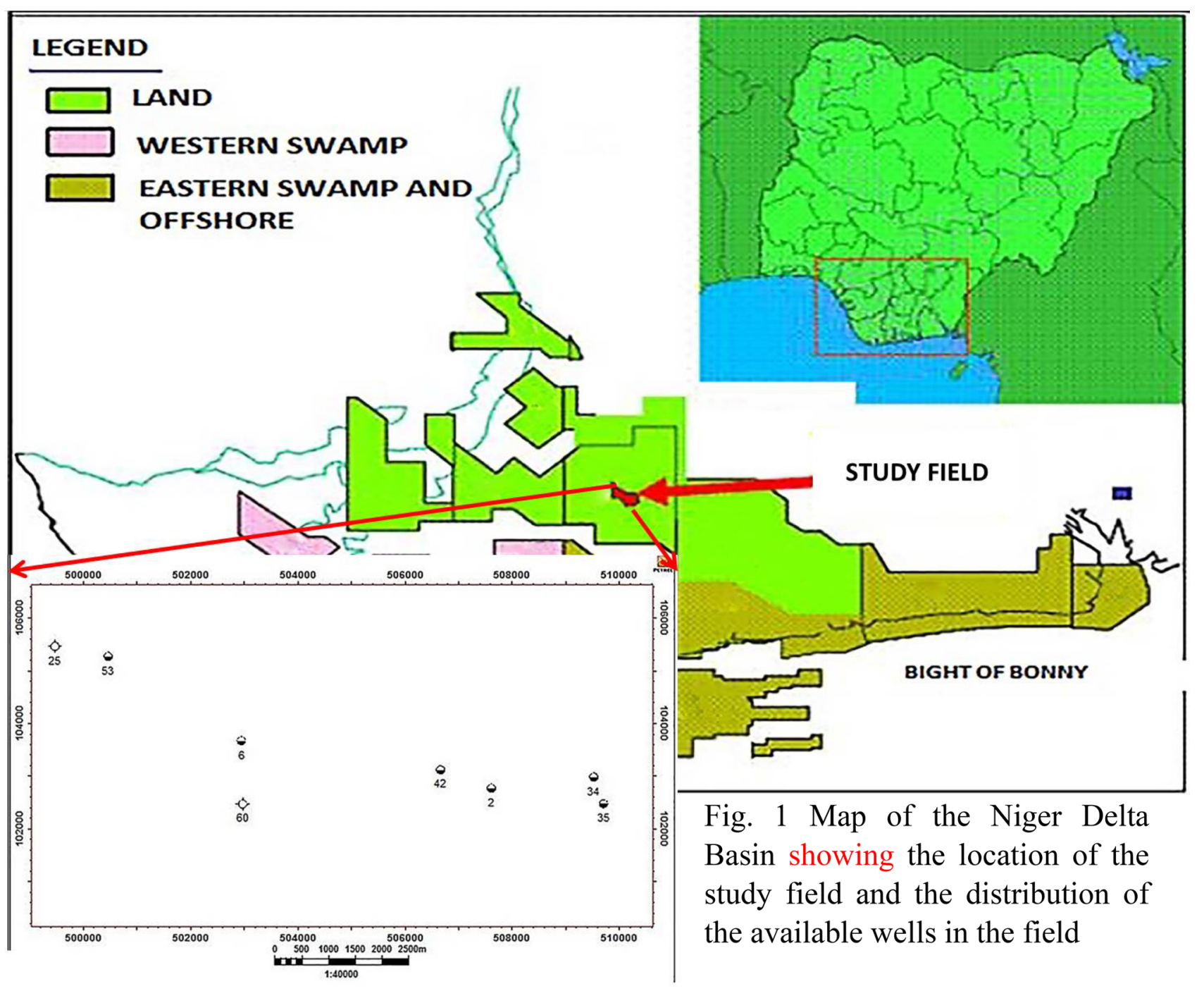

Fig. 1 Map of the Niger Delta Basin showing the location of the study field and the distribution of the available wells in the field

In this work, synthetic gathers $\left(0-35^{\circ}\right)$ were generated for both the in situ brine and hydrocarbon reservoirs using linear approximation of Zoeppritz equations (Zoeppritz 1919). The Zoeppritz equation calculates the amplitude of seismic waves and considers only plane-wave amplitudes of reflected P-waves and ignores inter-bed multiples and mode converted waves (Hampson and Russell 1999). Three steps were adopted in this study; synthetic gathers were initially generated at the reservoir tops, after which a reflection coefficient versus sine of incident angle plot was generated to categorize the sands using the Rutherford and Williams (1987) gas sand classification. AVO cross-plot analysis was also carried out to differentiate the reservoir as either brine or hydrocarbon filled.

Goodway et al. (1997) suggested some rock attributes for lithology and pore fluid discrimination, which were selected in this for cross-plot modelling. This technique was adopted since common fluid types and lithology tend to form discrete clusters in cross-plot space which helps in making a direct interpretation. Such separations are only possible if the cross-plotted rock properties are sensitive to variation in fluid changes and grain arrangement in the formation. Hence, some selected rock attributes were generated from well logs and cross-plotted using three models to test the applicability of rock physics techniques in the study field.

\section{Results and discussions}

The well-based feasibility analysis encompasses discussions of results for reflection pattern model, fluid substitution model, AVO model and rock physics cross-plot model. 


\section{Reflection pattern analysis}

For the reflection pattern analysis, deterministic wavelet was extracted from seismic to generate synthetic seismogram, whose signal responses were compared to change in acoustic impedance at geophysical boundaries in a correlation window (Fig. 2). The polarity of the data as observed for the sand tops is defined as a drop in acoustic impedance with depth defined as a soft kick typical of a negative response of the SEG convention. This response is as a result of the competency of the overlying shales across the interval displayed.

For AVO gas sand definition, response typical of either Class III or IV sands with a negative zero offset reflectivity that either increases or reduces in negativity with offset respectively, is expected within this depth interval on seismic, hence ruling out the possibility of misinterpreting response at the interface between compacted sand and under-compacted shale as class III or class IV within the zone of interest. Hence, no unusual response as reported by Avseth et al. (2016) is possible within this depth interval. Therefore, any such AVO response within our interval of study is expected to be depicting the presence of hydrocarbon bearing sands.

\section{Fluid substitution sensitivity modelling}

\section{Oil substitution modelling}

As observed in Fig. 3, the reservoir interval in the second track was defined by a low gamma ray and high resistivity response typical of hydrocarbon sands. In the P-wave tract, five curves are presented, which represents P-wave curve generated for brine or $100 \%$ water saturation, $5 \%$ oil saturation, $20 \%$ oil saturation, $80 \%$ oil saturation and the in situ saturation. It was observed that $\mathrm{P}$-wave value was highest for the brine filled case compared to when oil was introduced into the reservoir. This is because the additional mechanical strength brine contributes to the rock, which aids the propagation of sound wave as compared to the presence of hydrocarbon in the pore spaces of the same rock. Upon the substitution of $5 \%$ oil into the reservoir, the P-wave value dropped. Further increments in the saturation of oil in the reservoir lead to corresponding decrease in P-wave value.

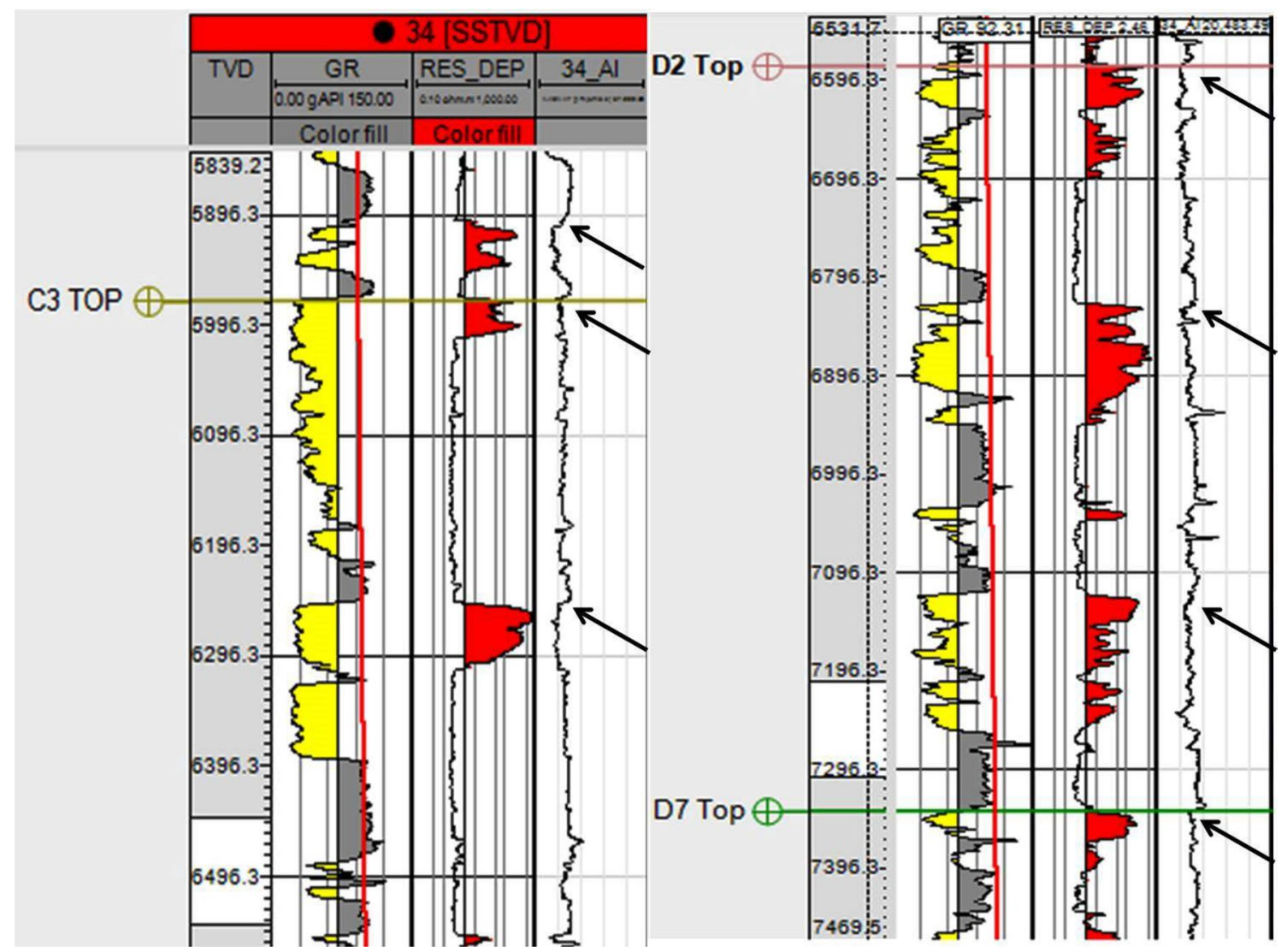

Fig. 2 Correlation window that displays gamma ray log, resistivity log, acoustic impedance $\log$ and positions of hydrocarbon bearing sand tops (arrows) within the depth interval of interest used for reflection pattern analysis 


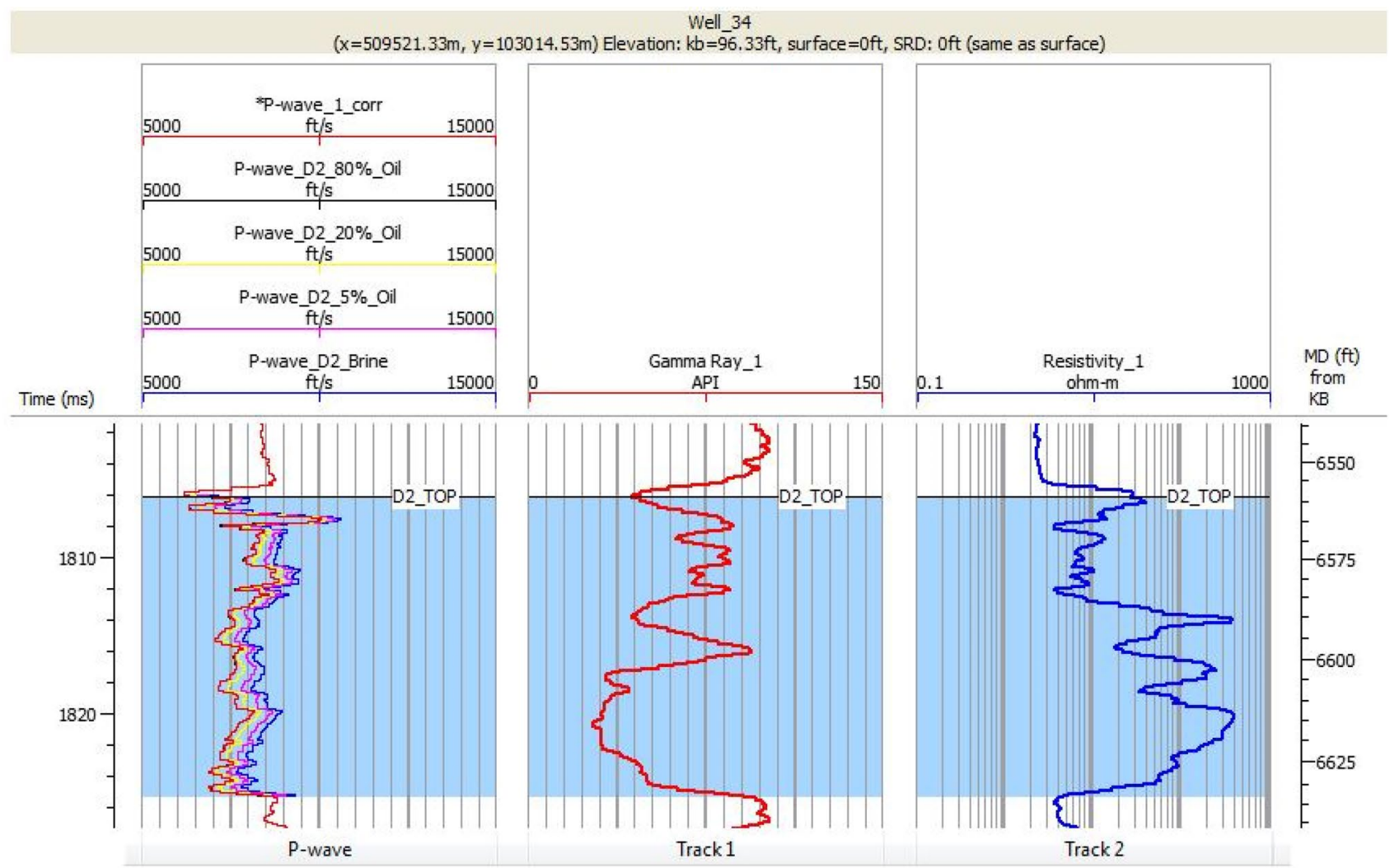

Fig. 3 The effect of various oil saturations on P-wave velocity in D2

This is indicates that the presence of various oil saturation could be detected and differentiated from brine filled sands using P-wave derived rock physics parameters both in wells and on seismic.

Another observation made from this fluid substitution result was that the P-wave value for the $80 \%$ oil saturation almost overlain the in situ curve. This implies that both scenarios might probably be of the same saturation and the technique can be adopted to estimate the potential hydrocarbon saturation in the reservoir experimentally, where the vital $\operatorname{logs}$ originally required for such purpose are either unavailable or compromised.

The effect of various oil saturation substitutions on density is presented in Fig. 4, which exhibited similar responses as observed with P-wave; a continuous increase in oil saturation leads to corresponding drop in density. An intriguing observation made here was the clear separation in density curves between the in situ saturation and $80 \%$ saturation, with the former having the lesser density value. This implies that the original reservoir saturation could be greater than $80 \%$ oil saturation.

Fluid substitution modelling was also done to test the sensitivity of $\mathrm{S}$-wave to the various oil saturations in the reservoir (Fig. 5). It was observed that irrespective of the oil saturation, the S-wave value remained relatively constant.
This is because the propagation of shear wave does not necessarily respond to change in fluid, but to change in the rock grain matrix since fluid in reality has close to zero resistance to shearing (Da-Xing 2017; Ogbamikhumi et al. 2017b).

Therefore, shear wave velocity does not depend on changes in fluid type or fluid saturation. In a mixed hydrocarbon and brine reservoir, the value of shear wave is therefore expected to be relatively similar within the fluid interval. Hence, shear wave and its derived rock physics attribute are expected to be a poor discriminant for fluid in a reservoir, but will be a very good indicator of lithology types.

\section{Gas substitution modelling}

Niger Delta Basin is a mixed hydrocarbon province, oil and gas bearing. In a typical oil field like the studied OSSY field, there exist the possibilities for reservoirs to be mixed hydrocarbon charged. Hence, it is important to model for gas scenarios also, which could aid the recognition of gas response in the undrilled areas of the field if gas happens to be present.

The same substitution process and template applied for the oil scenario was adopted for gas substitution presented in Figs. 6, 7, 8.

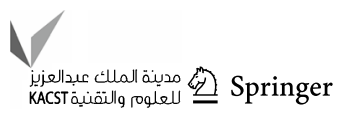




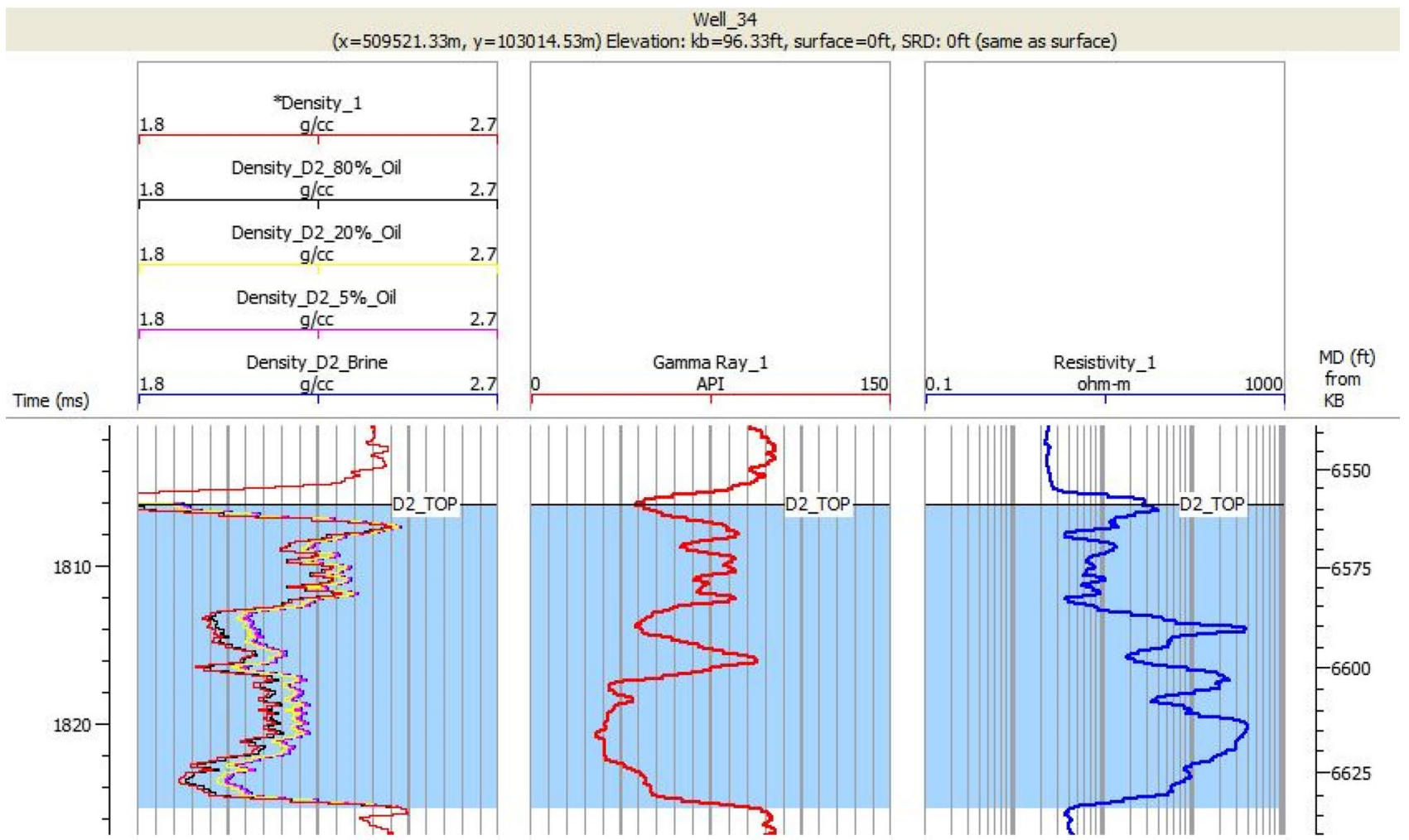

Fig. 4 The effect of various oil saturations on density log in D2 reservoir

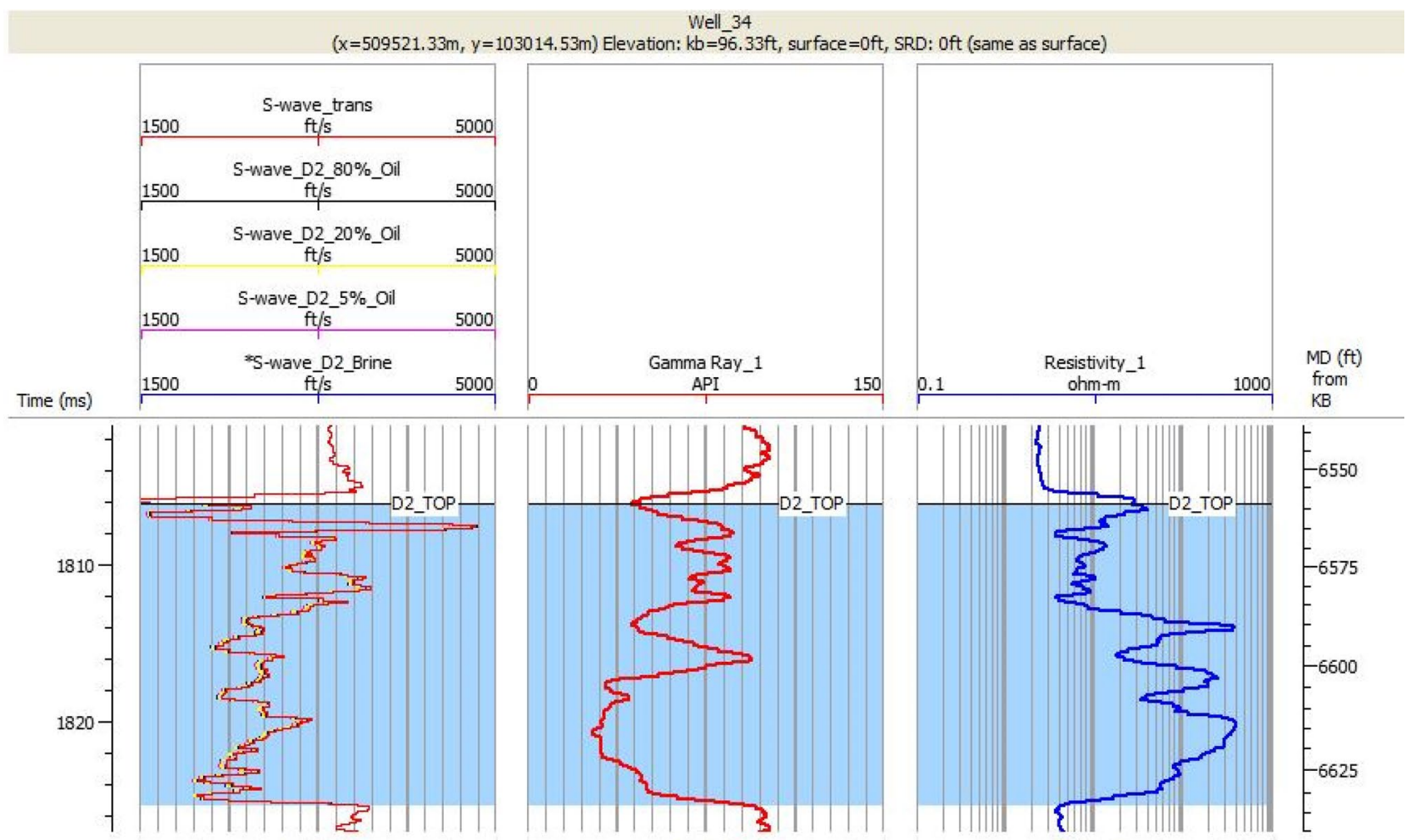

Fig. 5 The effect of various oil saturations on S-wave log in D2 reservoir 


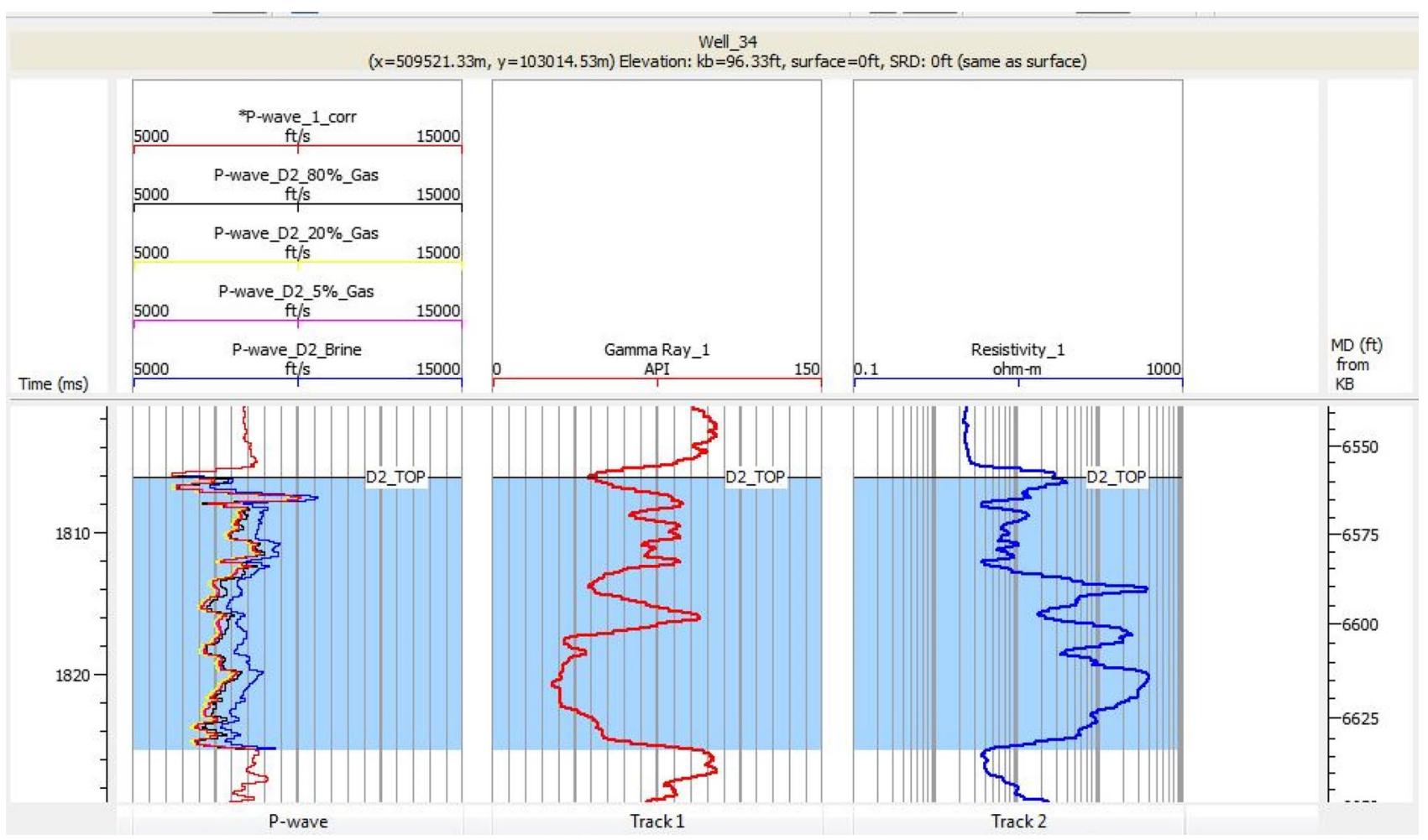

Fig. 6 The effect of various gas saturations on P-wave log in D2 reservoir

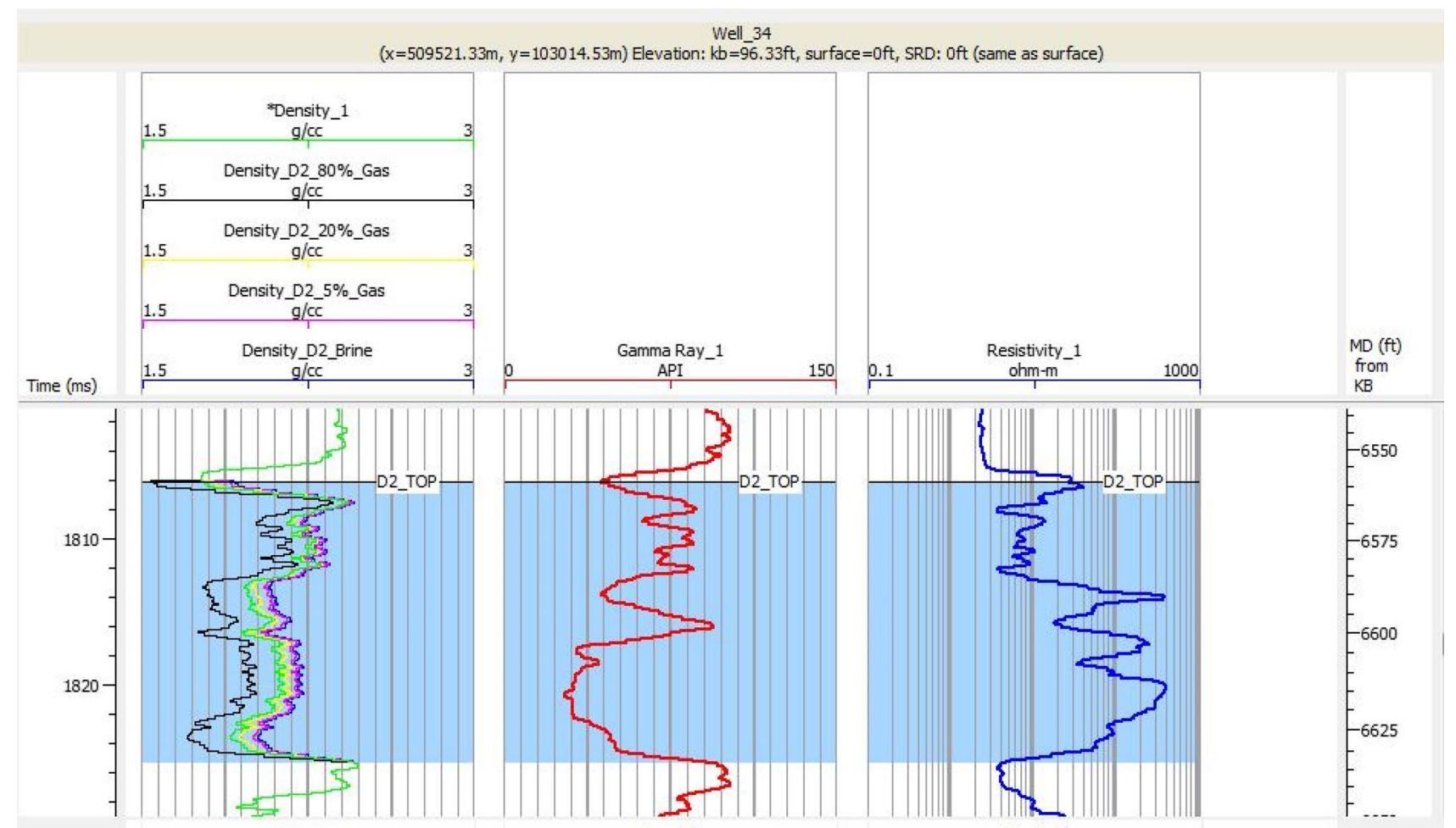

Fig. 7 The effect of various gas saturations on density $\log$ in D2 reservoir 


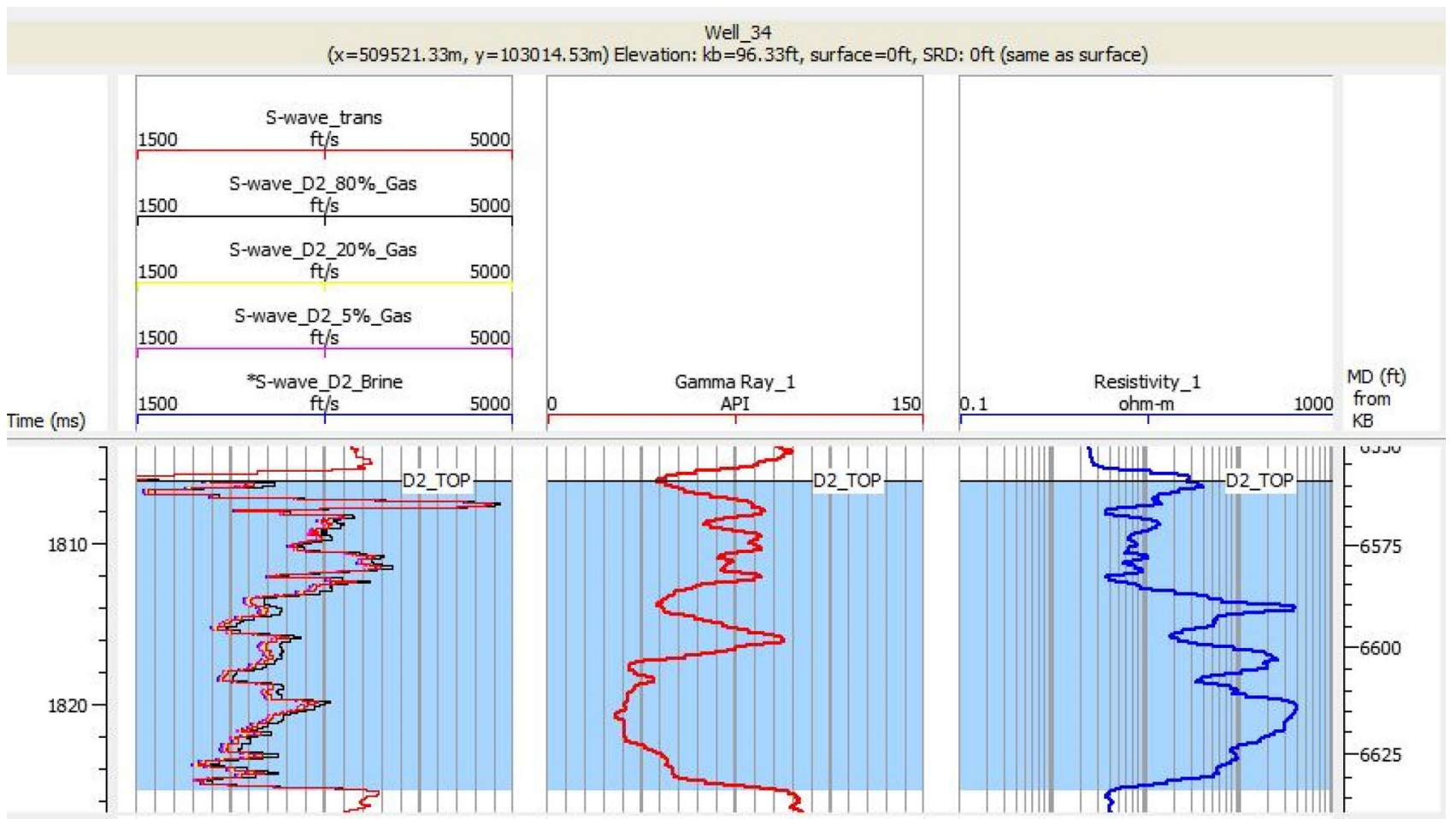

Fig. 8 The effect of various gas saturations on S-wave log in D2 reservoir

The substitution done to test the sensitivity of P-wave to gas saturations in Fig. 6 reveals that, for as little as 5\% increase in gas saturation, the value of P-wave fell drastically. Upon further increments, the saturation remained relatively constant. This suggests that although gas saturation would be easily detected on seismic for the reservoir in the field, it will be extremely difficult to differentiate between economical and sub-economical saturation of gas.

Gas substitution effect on density and S-wave logs presented in Figs. 7 and 8 both exhibited similar behaviours as observed in the case of the oil substitution scenario.

From the result of fluid substitution sensitivity analysis, it can be confidently concluded that quantitative interpretation techniques that rely on response of rock properties to fluid and lithology change can be conveniently applied to characterize reservoirs in the field.

\section{AVO Modelling}

Fluid substitution sensitivity analysis has demonstrated that quantitative interpretation techniques can be used to characterize the study field, and it is imperative to test the applicability of some quantitative interpretation techniques on wells, in order to establish their application on seismic for prospect evaluation, especially at the undrilled area of the field.
The modelling process was achieved by generating synthetic gathers that show variation of amplitude response as the angle of incident increases. This is a more detailed analysis compared to reflection pattern analysis that was done to understand the effect of compaction of shales on the AVO response at the top of the reservoirs directly underlying them. For the modelling process, two scenarios were tested: brine sand and hydrocarbon sand scenarios.

\section{AVO modelling for brine sand scenario}

The AVO modelling carried out for the brine sand scenario in (Fig. 9) shows the low gamma ray log response in track 1 used to define the reservoir interval and the low value of resistivity $\log$ in track 2 within the reservoir indicating a water bearing interval. The generated AVO synthetic for the in situ condition presented in the last track of Fig. 9 and the cross-plot of reflection coefficient versus sine of angle of incidence presented in Fig. 10 reveal a negative value for the zero offset reflection that becomes less negative with offset typical of the Rutherford and Williams class IV sands. This zero offset response was expected as demonstrated by our reflection pattern analysis, which initially revealed that the overlying shales within the interval of interest are more compacted than the reservoirs. Hence, a drop in impedance was expected at the shale-sand interface giving a negative response (meaning only a class III 


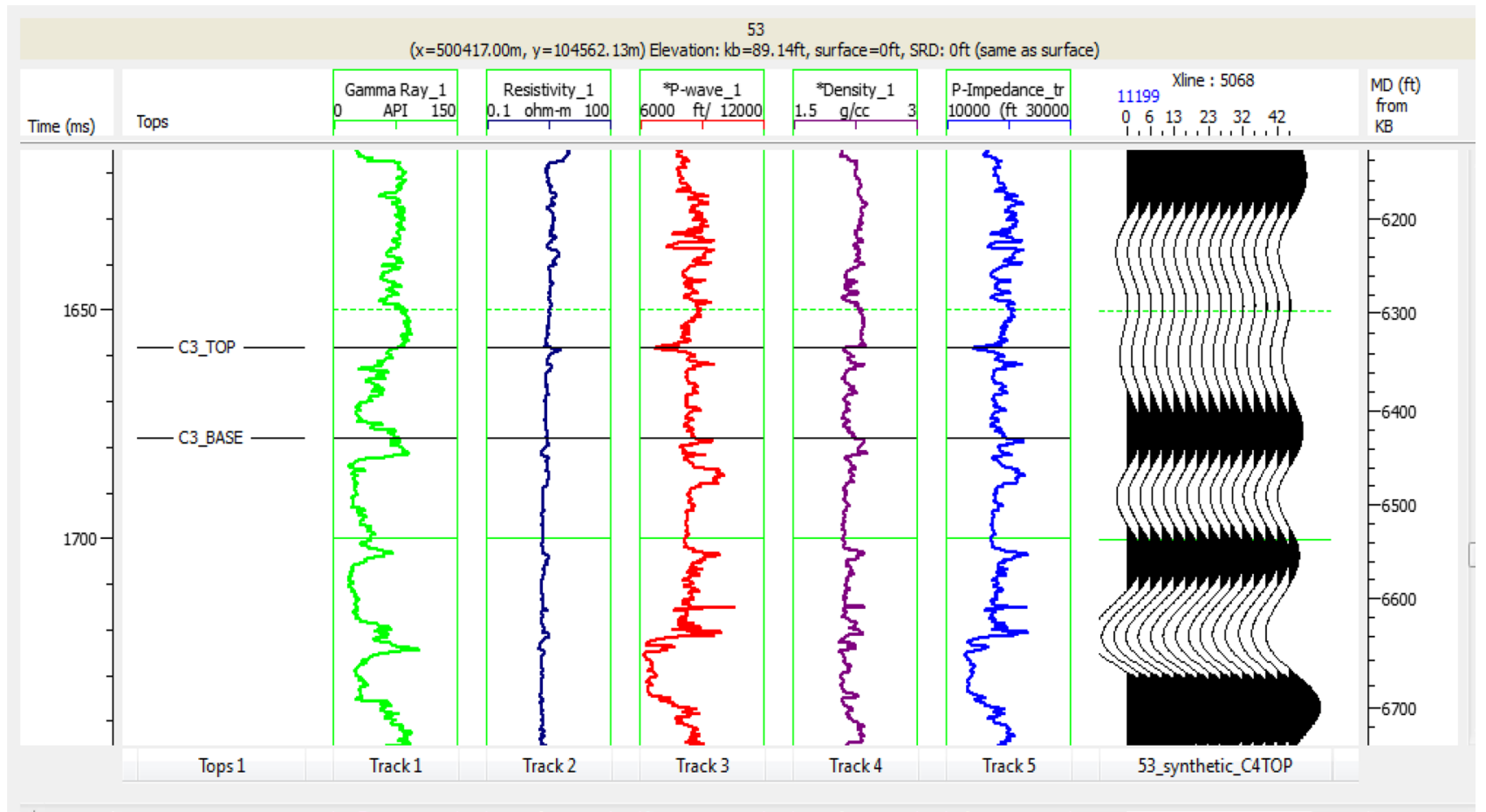

Fig. 9 Correlation panel showing well logs and AVO synthetic for brine filled C3 reservoir

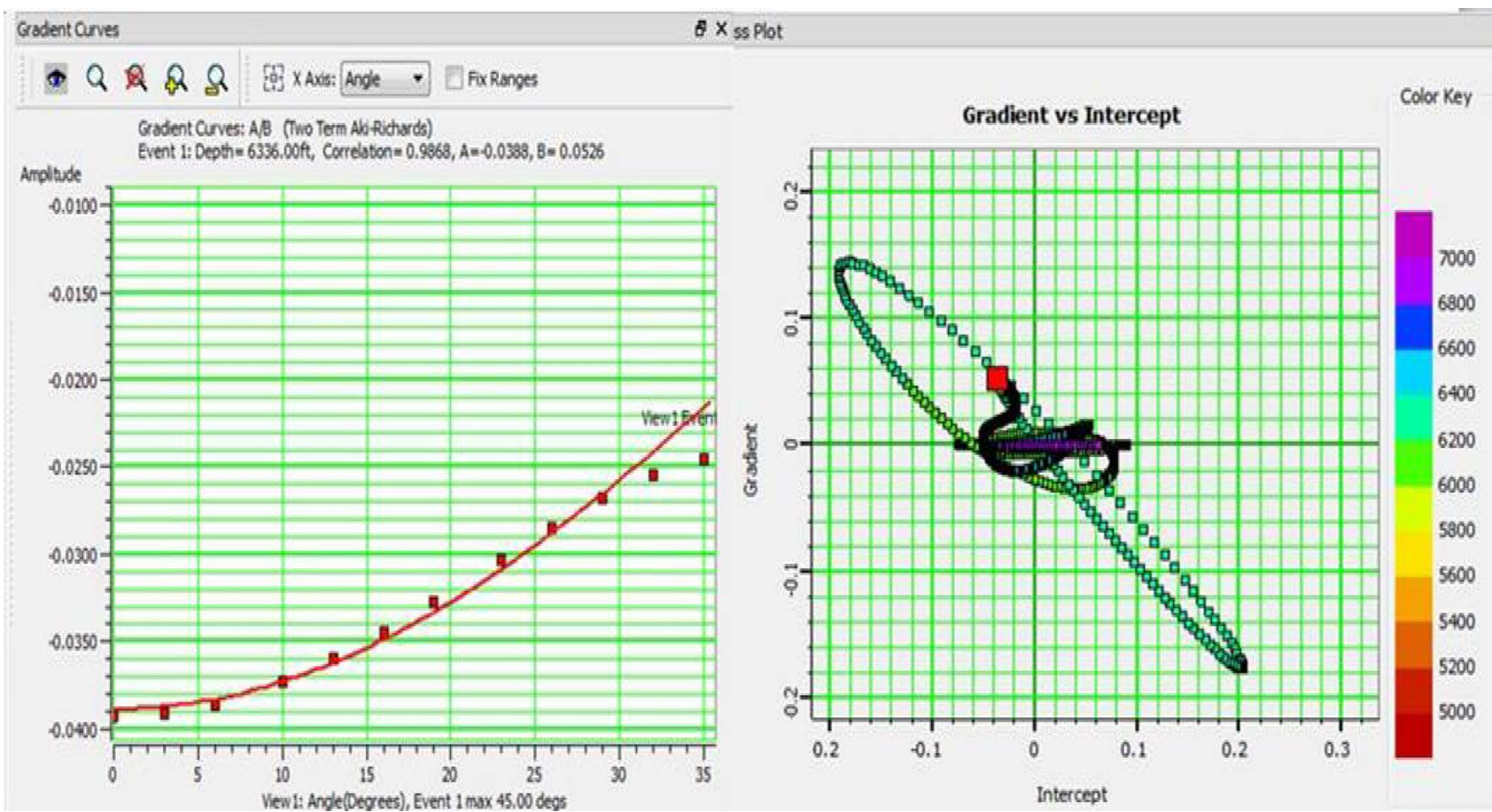

Fig. 10 Zero offset amplitude versus reflection angle plot (left) and gradient versus intercept plot (right) for C3 reservoir showing typical brine filled class IV AVO sand 
or class IV AVO sand response typical of the top of a reservoir was expected at that depth). The AVO cross-plot in Fig. 10 also shows that the reservoir top response falls along the background trend, indicating that the reservoir is brine filled.

\section{AVO modelling for hydrocarbon sand scenario}

The generated synthetics in Fig. 11 and the cross-plot of reflection coefficient versus sine of angle of incidence in Fig. 12 indicate a negative zero offset reflection that becomes less negative with offset typical of class IV AVO

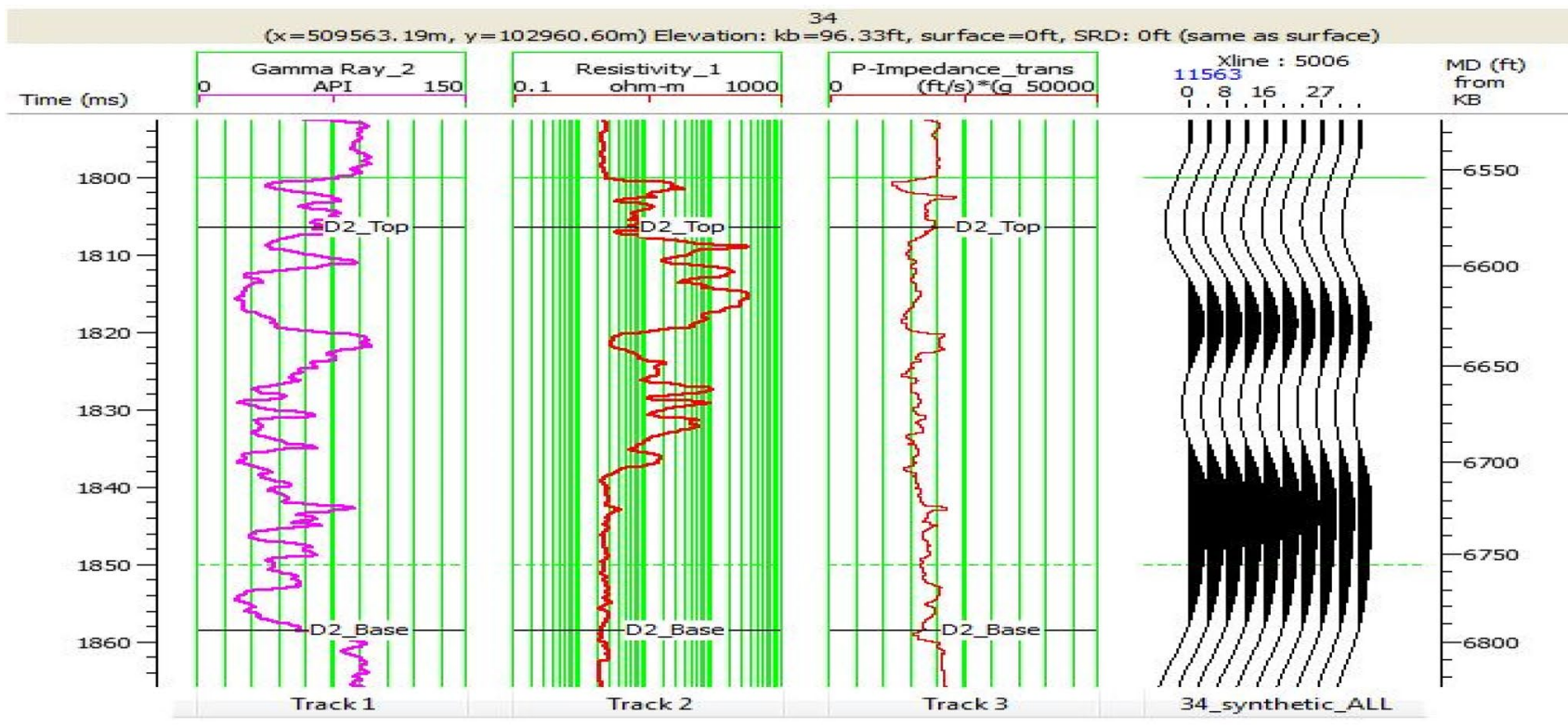

Fig. 11 Correlation panel showing well logs and AVO synthetic for hydrocarbon filled D2 reservoir

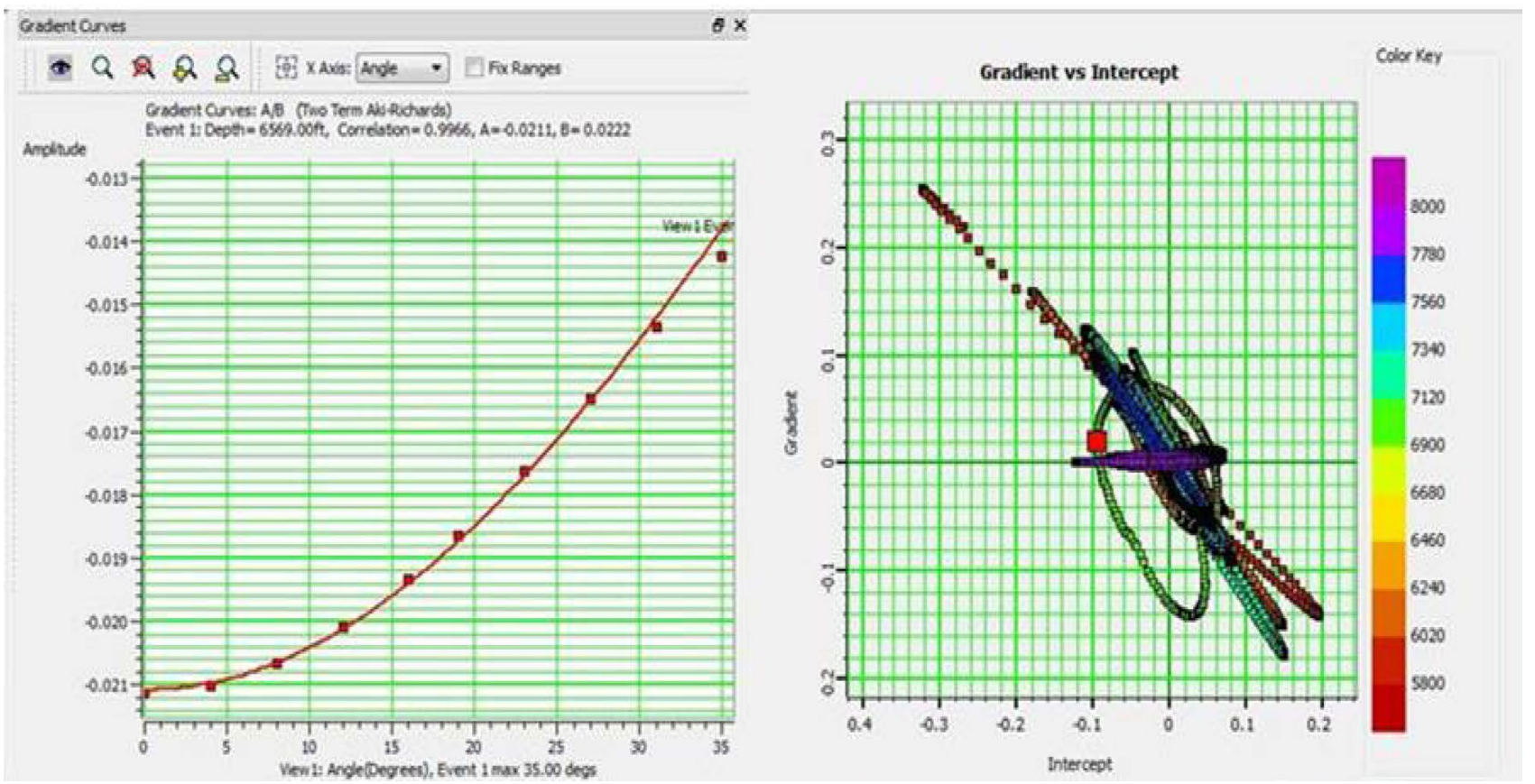

Fig. 12 Zero offset amplitude versus reflection angle plot (left) and gradient versus intercept plot (right) for D2 reservoir showing a typical hydrocarbon filled class IV AVO sand 
gas sand. The AVO cross-plot in Fig. 12 clearly indicated that the top of the reservoir plots on the first quadrant with negative intercept and near zero gradient typical of class IV AVO class is similar to the brine case. But in this case, the reservoir plots away from the background trend indicate the presence of hydrocarbon, as seen in the well log.

In summary, the overlying shale layers are compacted and the dominant AVO class sand expected within the depth interval of interest is the class IV sands, commonly described as a dim spot DHI on seismic. Dim spots are expressed as either on structure diming or off structure brightening on seismic. It has been demonstrated here that AVO technique is desirable to differentiate between brine and hydrocarbon filled sands in the undrilled zones on seismic data.

\section{Well-Based rock physics cross-plot analysis}

In most cases, rock properties respond preferably to variation in lithology and fluid content in sands, just as it has been demonstrated in this study (Singha and Chatterjee 2017; Abe et al. 2018). Hence, these rock properties alongside their derived attributes are expected to form different clusters in cross-plot space where such changes exist. MuRho, Lambda-Rho, Poisson ratio, P-impedance and Lambda$\mathrm{Rho} / \mathrm{Mu}-\mathrm{Rho}$ are secondary derived attributes from the three basic rock attributes. Li (2004) shows that LambdaRho decreases with increasing porosity and increasing gas content, for clastics. The parameter Mu-Rho is a lithology discriminant with high values indicative of sand lithology. The Poisson ratio is a fluid indicator because P-waves are sensitive to fluid changes, whereas $\mathrm{S}$-waves are not. The $\mathrm{P}$-wave impedance is more of a fluid indicator since both p-wave and density are sensitive to fluid change than lithology (Han et al. 2007). These rock properties were analysed using cross-plot techniques with attributes derived from well $\operatorname{logs}$, to ascertain the applicability of rock physics techniques for prospect evaluation from inversion result on seismic. The three cross-plot templates selected for the cross-plot analysis include: Mu-Rho versus Lambda-Rho plot, Lambda-Rho versus Lambda-Rho/ Mu-Rho cross-plot and Poisson ratio versus P-Impedance cross-plot. The cross-plots were colour coded with resistivity logs in order to discriminate between hydrocarbon bearing sands and brine filled sands. The colour scheme adopted within each cross-plotted interval, defined by the top and base of the sands, was common between the well log panel and cross-plot panel in Figs. 13, 14, 15.

\section{Mu-Rho versus Lambda-Rho cross-plot}

$\mathrm{Mu}$ is an S-wave derived parameter known as rigidity. It is expected to have values that are greater for sands than shales, since sand matrix exerts greater resistance to shearing than shale matrix. Its value is not affected by the nature of fluid in the pore spaces as demonstrated by the fluid substitution modelling; hence, the values for brine and hydrocarbon fill sand are expected to remain relatively constant. Lambda-Rho, on the other hand, is a P-wave derived parameter known as incompressibility. Since fluid contributes a reasonable amount to the total resistance exerted by a rock to compression, a change in fluid type and its saturation is important in determining the incompressibility of a rock. A systematic change in fluid type from brine to oil then to gas will lead to significant gradual reduction in the incompressibility of a rock (Azeem et al. 2017; Ogbamikhumi
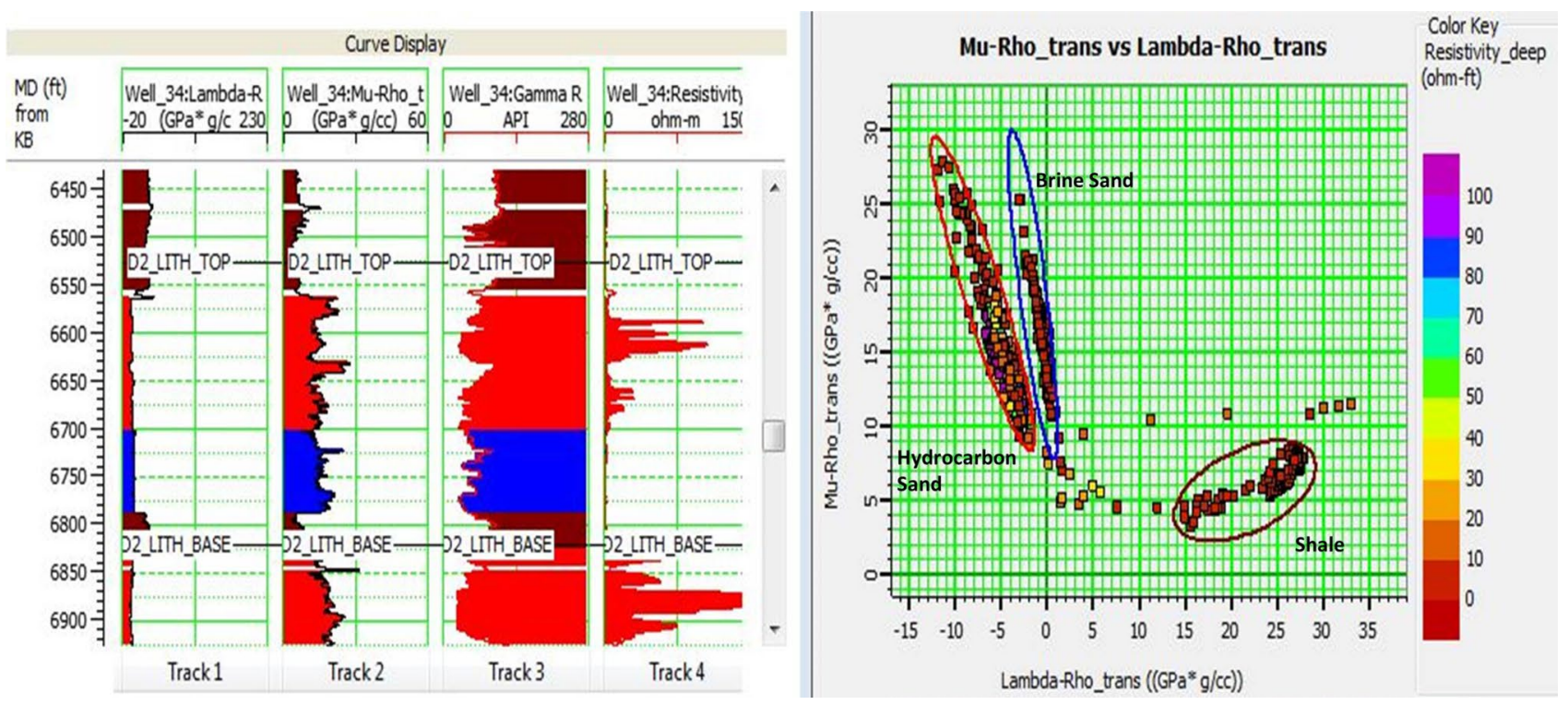

Fig. 13 Plot of Mu-Rho versus Lambda-Rho for D2 reservoir 

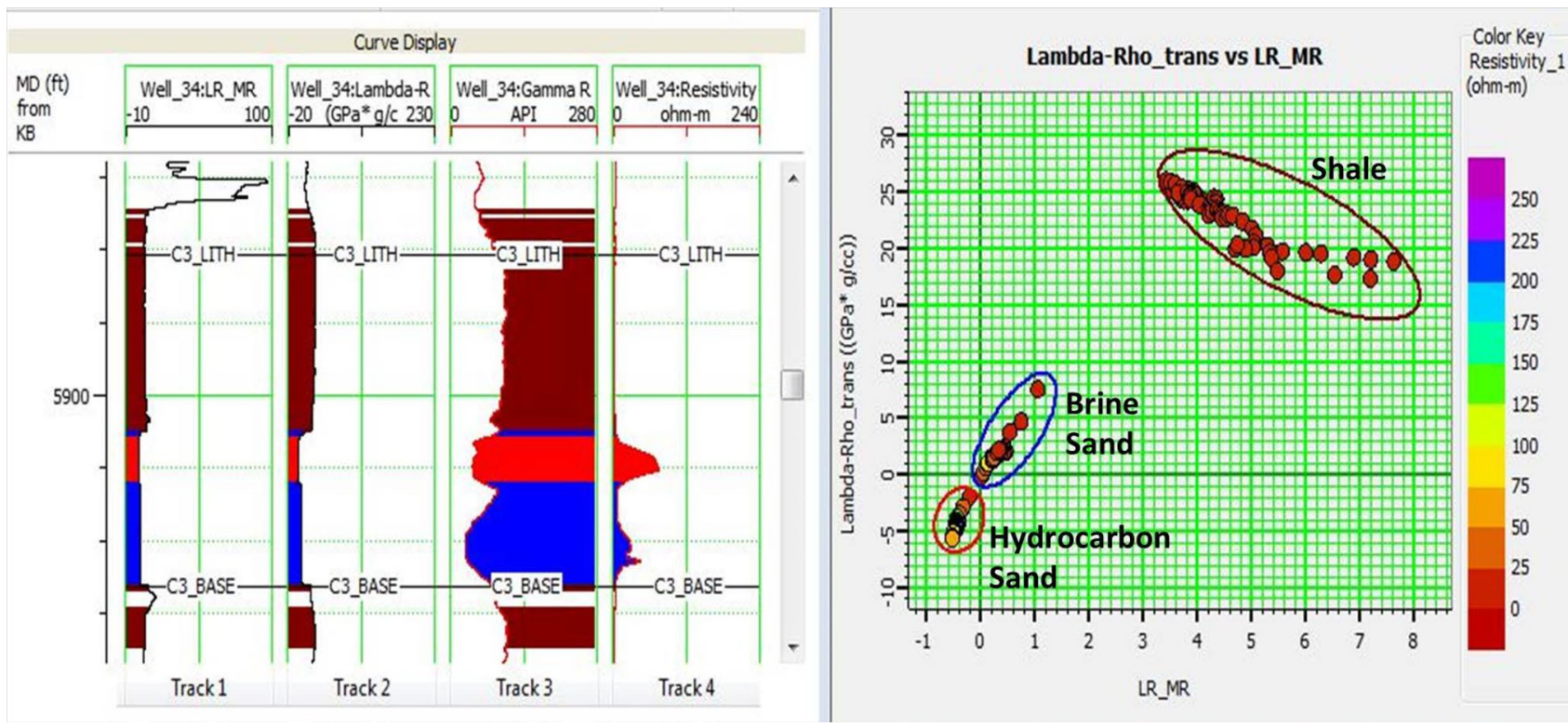

Fig. 14 Plot of Lambda-Rho versus Lambda-Rho/ Mu-Rho for C3 reservoir
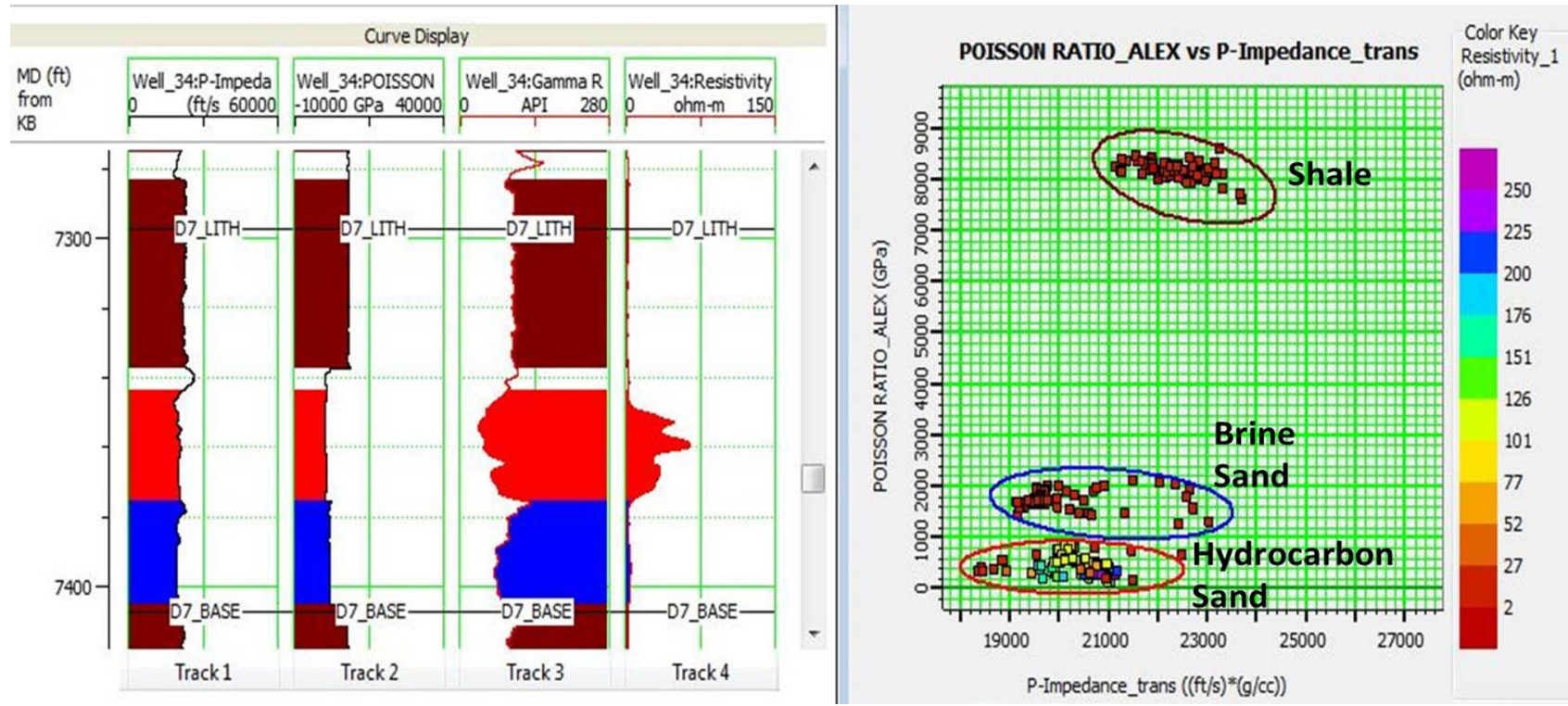

Fig. 15 Plot of Poisson ratio versus P-impedance plot for D7

et al. 2017b). Mu-Rho and Lambda-Rho are, respectively, products of these two parameters with the bulk density of the rock.

Therefore, a cross-plot of these two parameter within the depth interval of one of the reservoirs presented in Fig. 13 defined a zone with low Mu-Rho, high Lambda-Rho and low resistivity values, typical of shale lithology, similar to results obtained by Ekwe et al. (2012), while also working in the Niger Delta Basin. A second zone is demarcated with high Mu-Rho and low Lambda-Rho value typical of brine sand response. A third zone is defined with high Mu-Rho, very low Lambda-Rho and high resistivity value typical of a hydrocarbon bearing sands.

Although the rock attributes clearly discriminated between brine sand, hydrocarbon sand and shale as preempted from the fluid substitution sensitivity analysis, it was observed that the zone corresponding to hydrocarbon sand does not have resistivity value as high as expected for such response. We can therefore infer that the quality of the resistivity log is not very 
desirable. Hence, this cross-plot analysis can also be used to validate the quality of some petrophysical logs.

\section{Lambda-Rho versus Lambda-Rho/ Mu-Rho cross-plot}

The cross-plot of Lambda-Rho versus Lambda-Rho/ Mu-Rho is presented in Fig. 14. The ratio Lambda-Rho/ Mu-Rho is a complex ratio that presents a high value for shale, lower value for brine sand and a much more lower value for hydrocarbon bearing sands (Ogbamikhumi and Igbinigie 2020). The cross-plot reveals a zone defined by very high values for both lambda-Rho and Lambda-Rho/Mu-Rho attributes, which corresponds to the interval shaded brown in the well log panel defining shale lithology. Lower values of both parameters were observed for brine sand, and a much lower values of both attributes were recorded for hydrocarbon sand, similar to results obtained by researchers in the same basin (Omudu and Ebeniro 2005; Adeoti et. Al 2018). Thus, both parameters can be used to characterize lithology and fluid on well and seismic data.

\section{Poisson ratio versus $\mathrm{P}$-impedance cross-plot}

Poisson ratio is a more complex average of the $\mathrm{Vp} / \mathrm{Vs}$ ratio that discriminates shale lithology from sand with relatively greater values ( $\mathrm{Li}$ and Zhang 2018). For mix hydrocarbon and brine reservoir, a much lower value will be observed for hydrocarbon bearing sand as compared to brine sand. P-impedance is a product of P-wave velocity and density. Since both primary rock attributes responded in a similar manner to presence of hydrocarbon; reduction in their values as demonstrated in the fluid substitution sensitivity analysis, a product of both will have a multiplier effect that should conveniently differentiate hydrocarbon sand from brine sand under a normal condition.

The cross-plot of both parameters in Fig. 15 reveals very high values of Poisson ratio, a relatively high value of P-impedance and a very low value of resistivity, which defines shale lithology. Sand was defined by very low values of Poisson ratio and a relatively lower value of P-impedance compared to shale response. The hydrocarbon bearing interval is characterized by low values of P-impedance and very low values of Poisson ratio compared with the brine filled portion of the reservoir (Bodunde and Enikanselu 2019). Hence, Poisson ratio would serve as a better discriminator of fluid than P-impedance.

\section{Conclusion}

In this research work, several modelling techniques: reflection pattern models, fluid substitution models, AVO models and cross-plot models were employed to analyse the sensitivity of rock properties to changes in lithology and fluid types on wells in the studied field. This was to determine the extent to which quantitative seismic interpretation techniques can be applied on seismic for hydrocarbon prospect evaluation of reservoirs in the undrilled area of the field. Reflection pattern analysis pointed out that both the overlying and underlying shales bounding the sands of interest were more compacted than the sands. Hence, the expected AVO classes on seismic data in the field would be class III or class IV sands. Analysis of AVO models discriminated between brine and hydrocarbon presence confirmed that the sand tops within the depth interval of interest to be class IV sands. Fluid substitution modelling clearly reveals the sensitivity of the basic rock properties: P-wave, S-wave and density to changes in lithology, fluid types and saturations, suggesting that rock physics analysis on seismic would be effective for both oil and gas exploration in the field as demonstrated by Ekwe et al (2012). The well-based rock physics cross-plot modelling and analysis performed, confirmed that the rock properties of the reservoirs responded favourably to changes in fluid and lithology types by defining separate clusters for different lithology and fluid types. Hence, quantitative interpretation techniques would present dependable results for prospect evaluation on seismic, especially in the undrilled area of the field.

Acknowledgements We appreciate Shell Petroleum Development Company Nigeria, for releasing the data set used for this research. Special thanks also go to the Center of Excellence in Geosciences and Petroleum Engineering for making their workstations and software available to complete this work.

Funding The research was funded by Petroleum Trust Development Fund (PTDF), Nigeria.

\section{Declarations}

Conflict of interest We write to attest on behalf of the authors of the submitted manuscript titled 'Forward Modelling and Rock Properties Sensitivity Analysis for Hydrocarbon Exploration in OSSY Field.' The article has not been published in any form neither is it currently under review with any other journal.

Open Access This article is licensed under a Creative Commons Attribution 4.0 International License, which permits use, sharing, adaptation, distribution and reproduction in any medium or format, as long as you give appropriate credit to the original author(s) and the source, provide a link to the Creative Commons licence, and indicate if changes were made. The images or other third party material in this article are included in the article's Creative Commons licence, unless indicated otherwise in a credit line to the material. If material is not included in the article's Creative Commons licence and your intended use is not permitted by statutory regulation or exceeds the permitted use, you will need to obtain permission directly from the copyright holder. To view a copy of this licence, visit http://creativecommons.org/licenses/by/4.0/. 


\section{References}

Abe SJ, Olowokere MT, Enikanselu PA (2018) Development of model for predicting elastic parameters in 'bright'field, Niger Delta using rock physics analysis. NRIAG J Astronomy Geophys 7(2):264-278

Adeoti L, Allo OJ, Ayolabi EA, Akinmosin A, Oladele S, Oyeniran T, Ayuk MA (2018) Reservoir fluid determination from angle stacked seismic volumes in 'Jay'field, Niger Delta, Nigeria. J Appl Sci Environ Manag 22(4):453-458

Alvarez P, Alvarez A, MacGregor L, Bolivar F, Keirstead R, Martin $\mathrm{T}$ (2017) Reservoir properties prediction integrating controlledsource electromagnetic, prestack seismic, and well-log data using a rock-physics framework: case study in the Hoop Area, Barents Sea, Norway. Interpretation 5(2): SE43-SE60.

Assefa S, Mc Can C, Sothcott J (2003) Velocity of compressional and Shear waves in Limestone. Geophys Prospect 11:1-15

Avseth P A, Janke A, Horn F (2016) AVO inversion in explorationkey learning from a Norwagian Sea prospect. The Leading Edge: 405-414

Azeem T, Chun WY, Khalid P, Qing LX, Ehsan MI, Munawar MJ, Wei $X$ (2017) An integrated petrophysical and rock physics analysis to improve reservoir characterization of Cretaceous sand intervals in Middle Indus Basin. Pakistan J Geophys Eng 14(2):212-225

Bodunde SS, Enikanselu PA (2019) Integration of 3D-seismic and petrophysical analysis with rock physics analysis in the characterization of SOKAB field, Niger delta, Nigeria. J Petroleum Exploration Prod Technol 9(2):899-909

Chopra S, Castagna J P (2014) AVO: SEG. Publication, v. 2014: Tulsa, OK U.S.A. Society of Exploration Geophysicist: 15-25

Das B, Chatterjee R (2016) Porosity mapping from inversion of poststack seismic data. Georesursy 18(4):306-313

Da-Xing WANG (2017) A study on the rock physics model of gas reservoir in tight sandstone. Chin J Geophys 60(1):64-83

Dewar J (2001) Rock physics for the rest of us -An informal discussion: the Canadian society of exploration geophysicist recorder 5: 43-49

Ekwe A C, Onuoha K M, Osayande N (2012) Fluid and Lithology Discrimination Using Rock Physics Modelling And Lambdamurho Inversion: An Example from Onshore Niger Delta, Nigeria. In AAPG international conference and exhibition, Milan, Italy

Gassmann F (1951) Uber die elastizitat poroser medien: Vier. der Naturforsch. Gesellschaft 96:1-23

Goodway W, Chen T, Downton J (1997) Improved AVO fluid Detection and Lithology Discrimination using Lame Petrophysical Parameters, Extended Abstracts, Soc. Expl. Geophys., 67th Annual International Meeting, Denver

Hampson D, Russell B (1999) AVO theory: Hampson-Russell software services limited.

Han D H, Yao Q, Zhao H Z (2007) Complex properties of heavy oil sand: 77th annual international meeting, SEG, Expanded Abstracts: 1609-1613

Kumar R, Das B, Chatterjee R, Sain K (2016) A methodology of porosity estimation from inversion of post-stack seismic data. J Nat Gas Sci Eng 28:356-364

Li Y (2004) Lithology and partial gas saturation: 2004 CSEG National Convention,S054

Li H, Zhang J (2018) Well log and seismic data analysis for complex pore-structure carbonate reservoir using 3D rock physics templates. J Appl Geophys 151:175-183

Mavko G, Mukerji T, Dvorkin J (2020) The rock physics handbook. Cambridge University Press, Cambridge
Ogararue DO, Anine DO (2016) An integration of rock physics, AVO modelling and analysis for reservoir fluid and lithology discrimination in a Niger Delta deep water block. IOSR J Appl Geol Geophys 4:36-46

Ogbamikhumi A, Igbinigie NS (2020) Rock physics attribute analysis for hydrocarbon prospectivity in the Eva field onshore Niger Delta Basin. J Petrol Exploration Prod Technol: 1-12.

Ogbamikhumi A, Tralagba T, Osagiede EE (2017a) Time-lapse seismic monitoring of onshore reservoirs in Niger Delta, Field ' $\mathrm{K}$ ' as a case study. Nigerian J Environ Sci Technol 1:23-27

Ogbamikhumi A, Mabojemu RA, Odokuma-Alonge O (2017b) Avo modelling and crossplot analysis for reservoir characterization in montero field, central swamp depobelt, onshore Niger Delta Basin. Nigeria Journal of Science and Technology 37(3):15-23

Ogbamikhumi A, Andre-Obayanju O, Daniel GO (2018a) Fluid replacement modelling analysis for $\mathrm{C} 4$ reservoir characterisation onshore Niger Delta Basin. Scientia Africana 17(2):23-32

Ogbamikhumi A, Imasuen OI, Omoregbe OI (2018b) Inversion feasibility study for reservoir characterization of Osi field onshore Niger Delta Basin. FUW Trends Sci Technol J 3(2B):972-976

Ohaegbuchu HE, Igboekwe MU (2016) Determination of subsurface rock properties from AVO analysis in Konga oil field of the Niger Delta, Southeastern Nigeria. Model Earth Syst Environ 2:4

Omudu LM, Ebeniro JO (2005) Cross plot of rock properties for fluid fluid discrimination, using well data in offshore Niger Delta. Nigerian J Phys 17:16-20

Paul V, Marianne R (2006) A.V.O attribute analysis and seismic reservoir characterisation: EAGE; First Break 24

Rizwan M, Akhter G, Mustafa A, Bin Nisar U, Ashfaq K (2018) Amplitude versus offset (AVO) modelling and analysis for quantitative interpretation of porosity and saturation: a case study for Sawan gas field, middle Indus basin. Pakistan Geofísica internacional 57(2):151-160

Robinson N, Ford A, Howie J, Mncley D, Riviere M, Steward S, Thomas R (2005) 4D time lapse monitoring of chirag field. Lead Edge 24:928-932

Ross CP (2000) Effective AVO crossplot modelling: a tutorial. Geophysics 65:700-711

Rutherford SR, Williams RH (1987) Amplitude-versus-offset variations in gas sands. Geophysics 54:679-690

Short KC, Stauble AJ (1967) Outline of geology of Niger Delta. AAPG Bull 51:764-772

Singha D, Chatterjee R (2017) Rock physics modelling in sand reservoir through well log analysis, Krishna-Godavari basin, India. Geomech Eng 13(1):99-117

Smith TM, Sondergeld CH, Rai CS (2003) Gassmann fluid substitutions: A tutorial. Geophysics 68:430-440

Sohail GM, Hawkes CD (2020) An evaluation of empirical and rock physics models to estimate shear wave velocity in a potential shale gas reservoir using wireline logs. J Petrol Sci Eng 185:106666

Toshev M (2017) Study of the Capabilities of avo-methods for the detection of hydrocarbon accumulations. J Min Geol Sci 60:94-98

Uko ED, Emudianughe JE (2014) AVO modelling of the South-East Niger Delta. Nigeria Geophys Remote Sens 3(131):1-11

Zeoppritz K (1919) On the reflection and propagation of seismic waves. Erdbebenwellen VIIB, Gottinger Nachrichten I:65-85

Publisher's Note Springer Nature remains neutral with regard to jurisdictional claims in published maps and institutional affiliations. 